\title{
Identification of Genes Required for Growth of Escherichia coli MG1655 at Moderately Low pH
}

\author{
Bram Vivijs ${ }^{\dagger}$, Abram Aertsen and Chris W. Michiels*
}

Laboratory of Food Microbiology, Department of Microbial and Molecular Systems, and Leuven Food Science and Nutrition Research Centre (LFoRCe), KU Leuven, Leuven, Belgium

The survival of some pathotypes of Escherichia coli in very low $\mathrm{pH}$ environments like highly acidic foods and the stomach has been well documented and contributes to their success as foodborne pathogens. In contrast, the ability of $E$. coli to grow at moderately low $\mathrm{pH}$ has received less attention, although this property can be anticipated to be also very important for the safety of mildly acidic foods. Therefore, the objective of this study was to identify cellular functions required for growth of the non-pathogenic strain E. coli MG1655 at low pH. First, the role of the four E. coli amino acid decarboxylase systems, which are the major cellular mechanisms allowing extreme acid survival, was investigated using mutants defective in each of the systems.

OPEN ACCESS

Edited by: Abd El-Latif Hesham, Assiut University, Egypt

Reviewed by:

Swaine Chen,

Genome Institute of Singapore,

Singapore

Francisco Diez-Gonzalez, University of Georgia, USA

*Correspondence:

Chris W. Michie/s

chris.michiels@kuleuven.be

tPresent address:

Bram Vivijs,

Sanofi-Genzyme, Geel, Belgium

Specialty section:

This article was submitted to

Food Microbiology,

a section of the journal

Frontiers in Microbiology

Received: 18 July 2016 Accepted: 06 October 2016 Published: 25 October 2016

Citation:

Vivijs B, Aertsen A and Michiels CW (2016) Identification of Genes Required for Growth of Escherichia coli MG1655 at Moderately Low pH.

Front. Microbiol. 7:1672.

doi: 10.3389/fmicb.2016.01672
Only the lysine decarboxylase (CadA) was required for low pH growth. Secondly, a screening of 8544 random transposon insertion mutants resulted in the identification of six genes affecting growth in $\mathrm{LB}$ broth acidified to $\mathrm{pH} 4.50$ with $\mathrm{HCl}$. Two of the genes, encoding the transcriptional regulator $\mathrm{LeuO}$ and the elongation factor $P$ - $\beta$-lysine ligase EpmA, can be linked to CadA production. Two other genes, encoding the diadenosine tetraphosphatase ApaH and the tRNA modification GTPase MnmE, have been previously implicated in the bacterial response to stresses other than low $\mathrm{pH}$. A fifth gene encodes the LPS heptosyltransferase WaaC, and its mutant has a deep rough colony phenotype, which has been linked to reduced acid tolerance in earlier work. Finally, tat $C$ encodes a secA-independent protein translocase that exports a few dozen proteins and thus is likely to have a pleiotropic phenotype. For $m n m E$, apaH, epmA, and waaC, de novo in frame deletion and genetic complementation confirmed their role in low pH growth, and these deletion mutants were also affected in growth in apple juice and tomato juice. However, the mutants were not affected in survival in gastric simulation medium at $\mathrm{pH} 2.5$, indicating that growth at moderately low $\mathrm{pH}$ and survival of extremely low $\mathrm{pH}$ depend mostly on different cellular functions.

Keywords: Escherichia coli, acid stress, stress tolerance genes, genetic analysis, acidic foods

\section{INTRODUCTION}

In the food production chain, bacteria encounter various environmental stresses, such as heat, cold, desiccation, oxidants, or acids. Acid stress, in particular, can have various sources, such as the natural acidity of fruits and fruit-based foods, the formation of organic acids in fermented foods and the addition of organic acids to acidify foods or as food preservatives. Moreover, after food ingestion, bacteria become exposed to the extremely acidic environment of the stomach, with a $\mathrm{pH}$ typically ranging from 1.0 to 2.5 . The ability to adapt to environmental stresses allows bacteria to withstand the hostile conditions experienced in the food chain within certain limits. 
Adaptation to acid stress is especially relevant for infective foodborne pathogens. Indeed, in order to cause foodborne illness, these bacteria may not only become exposed to acid stress during food processing and storage, they also have to survive the harsh conditions in the stomach before they can infect the small intestine or the colon. Therefore, most studies related to acid stress in enteropathogens have mainly focused on the survival of important pathogens like Salmonella and enterohemorrhagic Escherichia coli (EHEC) upon extreme acid challenge for a few hours. These studies have revealed diverse mechanisms to survive extreme acid stress in these bacteria. One group of mechanisms is called acid resistance (AR), and is defined as the ability to survive an extreme acid challenge at pH 1.5-2.5 (Beales, 2004). AR mechanisms are active in E. coli but seem to be mostly lacking in Salmonella, which explains the lower level of AR in the latter. The other group of mechanisms is the acid tolerance response (ATR), and is defined as the ability to survive a normally lethal acid challenge at pH 3.0 - 3.5 after acid adaptation at moderately low $\mathrm{pH}$. These mechanisms have been mainly studied in Salmonella (Álvarez-Ordóñez et al., 2012).

Besides passive cytoplasmic buffering, five active stationaryphase AR systems have been described in E. coli (Kanjee and Houry, 2013). The AR1 system is referred to as the oxidative or glucose-repressed system and is only poorly understood. This system is activated under oxidative growth conditions and allows E. coli cells to survive a subsequent acid challenge. This is usually achieved by growing cells to stationary phase in a glucose-free complex medium at $\mathrm{pH} 5.5$, and by subsequently challenging them in a minimal medium, without an external supply of amino acid substrates, at $\mathrm{pH}$ 2.5. The other four AR systems (AR2-5) all rely on the activity of amino acid-dependent decarboxylase/antiporter systems and therefore require the presence of specific amino acids in the acid challenge medium. Each of these systems decarboxylates a specific amino acid (glutamate, arginine, lysine, or ornithine) to its corresponding amine ( $\gamma$-amino butyric acid (GABA), agmatine, cadaverine, or putrescine, respectively) by a cytoplasmic pyridoxal- $5^{\prime}$-phosphate (PLP)-dependent decarboxylase, and subsequently exchanges the decarboxylated product for new amino acid substrate via a cognate inner membrane-bound antiporter (Kanjee and Houry, 2013). The glutamate-dependent AR system (AR2) is by far the most potent $\mathrm{AR}$ system in $E$. coli and consists of the homologous inducible glutamate decarboxylases GadA and $\mathrm{GadB}$, and the glutamate/GABA antiporter GadC. In addition to the amino acid decarboxylase systems, the formate hydrogen lyase (FHL) complex, the adenosine deaminase Add and the glutaminase $\mathrm{YbaS}$ were also shown to contribute to $\mathrm{AR}$ in $E$. coli by promoting proton consumption (Noguchi et al., 2010; Sun et al., 2012; Lu et al., 2013). The ATR in Salmonella Typhimurium induces the expression of a large number of genes and prepares cells for lethal acid challenge by the activation of homeostatic mechanisms that maintain or raise the intracellular $\mathrm{pH}$, the production of acid shock proteins with a role in protecting or repairing damaged proteins and DNA, and modifying membrane composition to increase the barrier properties for protons (Álvarez-Ordóñez et al., 2012).
Compared to the survival of extremely low $\mathrm{pH}$, less is known about the mechanisms supporting growth of $E$. coli and other Enterobacteriaceae at moderately low $\mathrm{pH}(\mathrm{pH} 4.0-5.0)$, although these are at least equally important for food safety and food stability as the acid survival mechanisms. Several studies have reported growth of various members of the Enterobacteriaceae at surprisingly low $\mathrm{pH}$ values. For example, the $\mathrm{pH}_{\min }$ of 188 E. coli strains in lysogeny broth (LB) acidified with hydrochloric acid ranged from 3.8 to 4.3 (Haberbeck et al., 2015). Acidification of media with organic acids rather than hydrochloric acid increases the $\mathrm{pH}_{\min }$, but even in acidic foods containing organic acids, growth in this $\mathrm{pH}$ range has been reported. For example, strains of E. coli O157:H7 increased by $3.5 \log \mathrm{cfu} / \mathrm{ml}$ in apple cider of pH 3.6 in $16 \mathrm{~h}$ at $23^{\circ} \mathrm{C}$ (Ukuku et al., 2009), and by $2.5 \mathrm{log} \mathrm{cfu} / \mathrm{ml}$ in apple plugs of $\mathrm{pH} 3.3$ in $24 \mathrm{~h}$ at $25^{\circ} \mathrm{C}$ (Alegre et al., 2010). In the context of food safety, it is important to note that the $\mathrm{pH}$ boundaries supporting growth are temperature dependent. From an extensive study of the interaction of temperature and $\mathrm{pH}$ on growth of $E$. coli it was concluded that at suboptimal $\mathrm{pH}$ values (down to $\mathrm{pH}$ 5.0) $T_{\max }$ decreased strongly, $T_{\min }$ decreased slightly and $T_{\text {opt }}$ showed no clear trend (Baka et al., 2013). However, at $\mathrm{pH}$ values close to $\mathrm{pH}_{\min }, T_{\min }$ was found to increase (Haberbeck et al., 2015). In an earlier work, it was found that $\mathrm{pH}_{\min }$ of E. coli was constant between 25 and $37^{\circ} \mathrm{C}$ (Presser et al., 1998).

E. coli and other enterobacteria exhibit a transcriptional and translational response during growth at moderately low $\mathrm{pH}$ that induces mechanisms contributing to improved $\mathrm{pH}$ homeostasis, some of which overlap with the AR mechanisms. Several components of the electron transport chain which are coupled to proton translocation are upregulated during aerobic growth under mild acid stress (Maurer et al., 2005). The membrane potential that builds up as a result and that would impede sustained proton expulsion is dissipated by simultaneous uptake of $\mathrm{K}^{+}$. Further, the expression of enzymes that catalyze reactions which consume cytoplasmic protons, such as hydrogenases or amino acid decarboxylases, is increased under acidic conditions (Hayes et al., 2006). Interestingly, the products of lysine and ornithine decarboxylation (cadaverine and putrescine, respectively) also inhibit the $\mathrm{OmpF}$ and $\mathrm{OmpC}$ porins, thereby decreasing the outer membrane proton permeability (Dela Vega and Delcour, 1996). Growth at moderately low $\mathrm{pH}$ also enhances transport and metabolism of secondary carbon sources, such as sugars (e.g., ribose, arabinose, and fuculose) and sugar derivatives (e.g., galactitol, sorbitol, and gluconate) that produce fewer acids upon fermentation than glucose (Hayes et al., 2006). Finally, E. coli incorporates higher proportions of cyclopropane fatty acids during growth at low $\mathrm{pH}$, which reduces the proton permeability of the inner membrane under mild acid stress and has also be linked with a slightly increased ability to extrude protons upon acid stress (Shabala and Ross, 2008).

The objective of the current work was to conduct a comprehensive genetic analysis to identify (novel) genes required for growth of $E$. coli at moderately low $\mathrm{pH}$, and to determine whether these genes play a role in survival of extreme AR. First, 
the role of the known decarboxylase AR systems in growth at low $\mathrm{pH}$ was investigated, and subsequently a genome-wide screening for mutants deficient in low $\mathrm{pH}$ growth was conducted.

\section{MATERIALS AND METHODS}

\section{Bacterial Strains, Plasmids, and Oligonucleotides}

Bacterial strains and plasmids used in this chapter are listed in Table 1. E. coli MG1655 $\operatorname{gadA} / B$ and adiA were obtained via P1 transduction from E. coli EF522 and E. coli EF1022, respectively (Castanie-Cornet et al., 1999). Gene deletions were de novo constructed via a protocol described by Baba et al. (2006) using primers listed in Table 2. In this way, in-frame deletions encompassing the central region of the open reading frame from the second codon through and including the eighth codon before the C-terminus were created, leaving the start codon and translational signal for possible downstream genes intact. All deletions were verified by PCR using inwardly oriented primers complementary to the region left and right of the deleted genes (Table 2), and sequence analysis of the PCR products. Complementation plasmids were constructed by ligation of open reading frames into a NcoI and XbaI cut pTrc99A plasmid under control of the inducible $P_{\text {trc }}$ promoter, and correct insertion was verified using primers pTrc99A_seq_FW and pTrc99A_seq_REV.

TABLE 1 | Strains and plasmids used in this chapter.

\begin{tabular}{|c|c|c|}
\hline Strain or plasmid & Relevant features & Reference \\
\hline \multicolumn{3}{|c|}{ Escherichia coli MG1655 strains } \\
\hline Wild-type & $\mathrm{F}^{-} \lambda^{-} r p h-1$ & $\begin{array}{l}\text { Guyer et al., } \\
1981\end{array}$ \\
\hline $\operatorname{gad} A / B$ & $\begin{array}{l}\text { gadA::pRR10 (Ap) gadB::Km, obtained via } \\
\text { P1 transduction from E. coli EF522 }\end{array}$ & This work \\
\hline $\operatorname{adiA}$ & $\begin{array}{l}\text { adiA::MudJ }(\mathrm{Km}) \text {, obtained via P1 } \\
\text { transduction from E. coli EF1022 }\end{array}$ & This work \\
\hline$\Delta c a d A$ & In-frame deletion of cadA & This work \\
\hline$\Delta s p e F$ & In-frame deletion of speF & This work \\
\hline$\Delta$ waaC & In-frame deletion of waaC & This work \\
\hline$\Delta$ leuO & In-frame deletion of leuO & This work \\
\hline$\Delta m n m E$ & In-frame deletion of $m n m E$ & This work \\
\hline$\Delta a p a H$ & In-frame deletion of apaH & This work \\
\hline$\Delta e p m A$ & In-frame deletion of epmA & This work \\
\hline \multicolumn{3}{|l|}{ Plasmids } \\
\hline pTrc99A & $\begin{array}{l}\text { Cloning vector carrying IPTG-inducible trc } \\
\text { promoter }\left(P_{\text {trc }}\right) ; \mathrm{Ap}^{R}\end{array}$ & $\begin{array}{l}\text { Amann et al., } \\
1988\end{array}$ \\
\hline pKD13 & $\begin{array}{l}\text { Template plasmid containing kan gene } \\
\text { flanked by FRT sites; } \mathrm{Km}^{R} \mathrm{Ap}^{R}\end{array}$ & $\begin{array}{l}\text { Datsenko and } \\
\text { Wanner, } 2000\end{array}$ \\
\hline pKD46 & $\begin{array}{l}\text { Plasmid expressing } \gamma, \beta \text {, and exo } \\
\text { recombination genes of phage } \lambda \text { under } \\
\text { control of } P_{B A D} \text {; temperature-sensitive } \\
\text { replicon; } A p^{R}\end{array}$ & $\begin{array}{l}\text { Datsenko and } \\
\text { Wanner, } 2000\end{array}$ \\
\hline pCP20 & $\begin{array}{l}\text { Plasmid expressing the FLP (flippase) gene, } \\
\text { directing recombination of FRT sites; } \\
\text { temperature-sensitive replicon; } \mathrm{Ap}^{R} \mathrm{Cm}^{R}\end{array}$ & $\begin{array}{l}\text { Datsenko and } \\
\text { Wanner, } 2000\end{array}$ \\
\hline
\end{tabular}

\section{Screening for Mutants of E. coli MG1655 Affected in Growth at Moderately Low pH}

A random knockout library of E. coli MG1655 was constructed using $\lambda \mathrm{NK} 1324$, which carries a mini-Tn10 transposon (1.4 kb) with a $\mathrm{Cm}$ resistance gene and a mutant transposase with relaxed target specificity, according to the protocol described by Kleckner et al. (1991). To maximize randomness and genome coverage, the mutant collection was assembled from 89 independent transposon mutagenesis experiments from each of which 96 mutants were isolated (i.e., a total of 8544 mutants). The mutants were stored in microplates at $-20^{\circ} \mathrm{C}$. To screen for growth at moderately low $\mathrm{pH}$, the mutant library was first inoculated into microplates containing $300 \mu \mathrm{l} \mathrm{LB}$ broth $(10 \mathrm{~g} / \mathrm{l}$ tryptone, $5 \mathrm{~g} / \mathrm{l}$ yeast extract, $5 \mathrm{~g} / \mathrm{l} \mathrm{NaCl}$ ). These plates were covered with a foil and incubated overnight at $37^{\circ} \mathrm{C}$. Then, the stationary-phase cultures were thousandfold diluted in microplates containing $300 \mu \mathrm{l} \mathrm{LB}$ acidified to $\mathrm{pH} 4.50$ with $\mathrm{HCl}$, and the plates were covered with a foil and incubated at $30^{\circ} \mathrm{C}$ for $24 \mathrm{~h}$, when the $\mathrm{OD}_{600}$ was measured. Transposon insertion sites were determined using the method of Kwon and Ricke (2000). Briefly, genomic DNA of the mutants was isolated, digested with NlaIII and ligated with a Y-shaped linker, composed of oligonucleotides linker 1 and linker 2. Next, a PCR amplification was carried out using a transposon-specific primer (NK_Cm_DWN) and a primer specific to the Y-shaped linker (Y linker primer). The PCR product was subsequently sequenced using the transposonspecific primer and the insertion site was determined based on the known genome sequence of $E$. coli MG1655.

\section{Determination of Growth Curves Via OD Measurements}

Escherichia coli strains were grown overnight to stationary phase in $4 \mathrm{ml} \mathrm{LB}$ at $37^{\circ} \mathrm{C}$ and thousandfold diluted in fresh $\mathrm{LB}$ acidified with $\mathrm{HCl}$ to the required $\mathrm{pH}$. Culture volumes of $300 \mu \mathrm{l}$ were transferred to the wells of a microplate, which was sealed with a cover foil and incubated in a Multiskan Ascent plate reader (Thermo Labsystems, Helsinki, Finland) at 30 or $37^{\circ} \mathrm{C}$, and the $\mathrm{OD}_{630}$ was automatically measured every $15 \mathrm{~min}$. The growth curves were fitted by the model of Baranyi and Roberts (1994), using the Excel add-in package DMFit (Institute of Food Research, Norwich, UK). For the decarboxylase mutants, growth curves were also recorded in a similar way in M9 medium (Sambrook et al., 1989) supplemented with 0.2\% glucose, 0.1\% casamino acids, and $1 \mathrm{mg} / \mathrm{l}$ thiamine, and adjusted to $\mathrm{pH} 4.80$ with $\mathrm{HCl}$, and to which $5 \mathrm{mM} \mathrm{L-glutamic} \mathrm{acid,} \mathrm{L-arginine,} \mathrm{L-}$ lysine, or L-ornithine were added when required. In this case, wells were covered with $50 \mu \mathrm{l}$ paraffin oil to create anoxic conditions required for decarboxylase activity.

\section{Determination of Growth Curves Via Plate Counts}

Stationary-phase cultures, grown overnight in $4 \mathrm{ml} \mathrm{LB}$ at $37^{\circ} \mathrm{C}$, were 100,000-fold diluted in test tubes containing $10 \mathrm{ml} \mathrm{LB}$, apple or tomato juice that had been first adjusted to specific $\mathrm{pH}$ values with $\mathrm{HCl}$ or $\mathrm{NaOH}$. The suspensions in $\mathrm{LB}$ were transferred to microplates (multiple $300 \mu \mathrm{l}$ samples) and sealed with a 
TABLE 2 | Primers used in this chapter.

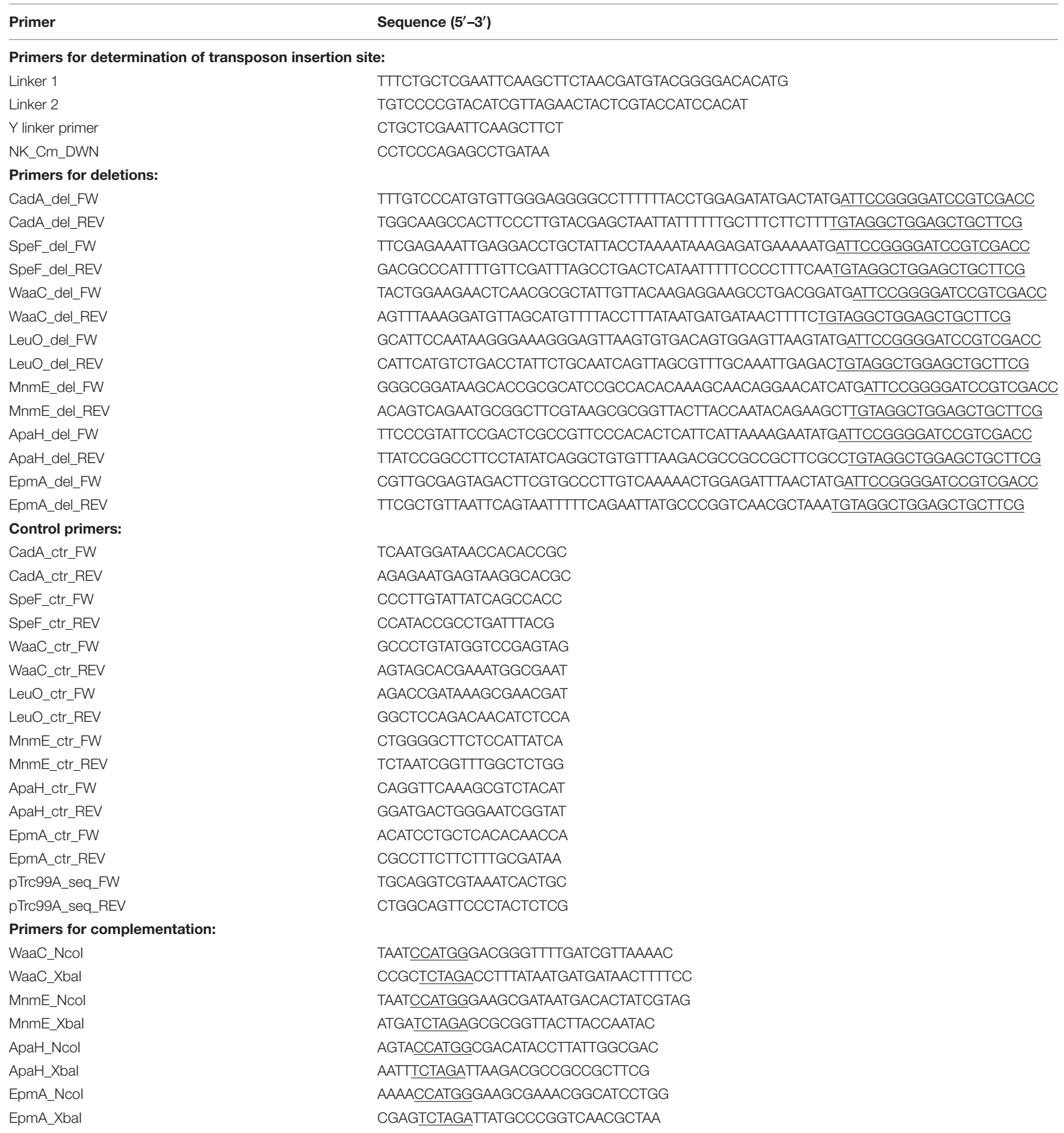

cover foil. The test tubes with acidic juices and the microplates were incubated without shaking at 20 and $30^{\circ} \mathrm{C}$, respectively. At regular time points, $300 \mu \mathrm{l}$ samples were taken, serially diluted in potassium phosphate buffer $(10 \mathrm{mM}$; $\mathrm{pH} 7.00)$ and subsequently spotted $(5 \mu \mathrm{l})$ on LB agar. After $24 \mathrm{~h}$ of incubation at $37^{\circ} \mathrm{C}$, the colony-forming units were determined.

\section{Acid Challenge (Survival) Assay}

Stationary-phase cultures grown overnight at $37^{\circ} \mathrm{C}$ in $4 \mathrm{ml}$ LB were hundredfold diluted in test tubes containing $4 \mathrm{ml}$ of simulated gastric fluid (Beumer et al., 1992). The composition of this medium was $8.3 \mathrm{~g} / \mathrm{l}$ bacteriological peptone, $3.5 \mathrm{~g} / \mathrm{l}$ glucose, $2.05 \mathrm{~g} / \mathrm{l} \mathrm{NaCl}, 0.6 \mathrm{~g} / \mathrm{l} \mathrm{KH}_{2} \mathrm{PO}_{4}, 0.11 \mathrm{~g} / \mathrm{l} \mathrm{CaCl} 2,0.37 \mathrm{~g} / \mathrm{l} \mathrm{KCl}$, 
$0.05 \mathrm{~g} / \mathrm{l}$ bile salts (Oxoid, Basingstoke, UK), $0.1 \mathrm{~g} / \mathrm{l}$ lysozyme (66200 U/mg, Fluka, Buchs, Switzerland), and $13.3 \mathrm{mg} / \mathrm{l}$ pepsin (47 U/g, Fluka, Buchs, Switzerland), and the $\mathrm{pH}$ was adjusted to 2.50 with $\mathrm{HCl}$. The suspensions were incubated at $37^{\circ} \mathrm{C}$ for 6 h. Every hour, $100 \mu \mathrm{l}$ samples were taken, serially diluted in potassium phosphate buffer (10 mM; pH 7.00) and subsequently plated on LB agar. D-values (time required for a 10-fold reduction in viable cells) were determined by identification of the log-linear Bigelow model (for the $\Delta w a a C$ mutant) or the log-linear model with shoulder (for the wild-type and other deletion mutants) using GInaFiT (Geeraerd et al., 2005).

\section{Statistical Analysis}

All experiments were carried out in triplicate using cultures grown from different colonies on a single agar plate. Mean values of different strains or treatments were compared by Student's $t$-test and differences were considered significant when a $p$-value of $<0.05$ was obtained.

\section{RESULTS}

\section{Role of E. coli Amino Acid Decarboxylase Systems in Growth at Moderately Low pH}

First, we investigated whether the addition of the four amino acid substrates of the AR systems 2, 3, 4, and 5 (glutamic acid, arginine, lysine, and ornithine, respectively) improves growth of E. coli MG1655 at a low initial pH. This was done in M9 minimal medium to reduce the basal levels of these amino acids compared to rich media like LB. However, $0.1 \%$ casamino acids were added to stimulate growth. The initial $\mathrm{pH}$ of the medium was set at 4.80 , and final $\mathrm{pH}$ values were recorded as an indication of decarboxylase activity (Figure 1). The experiments with the decarboxylase mutants were conducted at $37^{\circ} \mathrm{C}$. Although this temperature is not very relevant to most conditions at which foods are stored, it is more challenging for growth of $E$. coli at low $\mathrm{pH}$ than $30^{\circ} \mathrm{C}$, and therefore expected to allow a more sensitive detection of any deficiencies in the mutants' capacity to grow at low $\mathrm{pH}$ (see below).

The addition of arginine or ornithine to the acidified M9 medium did not result in growth improvement of $E$. coli MG1655 at initial $\mathrm{pH} 4.80$ and also did not affect the final $\mathrm{pH}$ values of the cultures. On the other hand, the addition of lysine, and to a smaller extent glutamate, enhanced growth and also resulted in a significantly higher final $\mathrm{pH}$ value. To further investigate whether the corresponding decarboxylase enzymes are involved in this growth improvement, the experiment was repeated with E. coli MG1655 strains deficient in the decarboxylases of the AR systems $2,3,4$, and $5(\operatorname{gad} A / B, \operatorname{adi} A, \Delta c a d A$, and $\Delta s p e F$, respectively) (Figure 2). The growth curves and final $\mathrm{pH}$ values of the adiA and $\triangle s p e F$ mutants, with or without addition of arginine or ornithine, respectively, were not significantly different from those of the wild-type strain (data not shown). Further, a small growth improvement and $\mathrm{pH}$ increase was observed when glutamate was supplied to cultures of the $\operatorname{gad} A / B$ mutant, but this was not different from the wild-type strain, indicating that the stimulating effect of glutamate on growth at $\mathrm{pH} 4.80$ was not due to its decarboxylation. On the other hand, supplementation with lysine did no longer improve growth and increase final $\mathrm{pH}$ in the $\triangle \mathrm{cadA}$ mutant (Figure 2), suggesting that the low $\mathrm{pH}$ growth enhancing effect of lysine on E. coli is due to lysine decarboxylation by CadA.

Subsequently, we investigated whether the decarboxylase enzymes play a role to support growth of E. coli MG1655 in a complex medium (LB) at low $\mathrm{pH}$ (Figure 3). Knockout of $\operatorname{gad} A / B$, adiA, or $s p e F$ did not result in diminished growth in $\mathrm{LB}$ at $\mathrm{pH} 4.40$ or 4.60 . However, the final $\mathrm{pH}$ values for the $\operatorname{gad} A / B$ and $a d i A$ mutants were significantly lower than those of the wild-type strain, indicating that the glutamate and arginine decarboxylases are active during growth of MG1655 under these conditions. Deletion of cadA clearly impaired growth in acidified $\mathrm{LB}$ and resulted in the lowest final $\mathrm{pH}$ values. Finally, deletion of speF did not influence E. coli growth or final $\mathrm{pH}$.

\section{Genome-Wide Screening for Mutants of E. coli MG1655 Affected in Growth in LB at Low pH}

As an open approach to identify novel genes involved in moderately low $\mathrm{pH}$ growth, a random transposon insertion mutant library of E. coli MG1655 was constructed and screened. To identify suitable screening conditions, the wild-type strain was first grown in $\mathrm{LB}$ acidified with $\mathrm{HCl}$ to different initial $\mathrm{pH}$ values (data not shown). This screening was done at $30^{\circ} \mathrm{C}$, because, as mentioned before, this makes the selection more relaxed than $37^{\circ} \mathrm{C}$ and thus ensures that only the most sensitive mutants are picked up.

The lowest $\mathrm{pH}$ at which growth was observed in this experiment was 4.20 , and the $\mathrm{pH}$ for this culture increased to 5.10 after 72 h. From pH 4.20 to 4.50 , the growth rates and final $\mathrm{OD}_{630}$ increased rapidly, while a further increase of $\mathrm{pH}$ above $4.50 \mathrm{had}$ comparatively less effect on growth. Based on these observations, a $\mathrm{pH}$ value of 4.50 was chosen for the screening in combination with an incubation time of $24 \mathrm{~h}$. Although this $\mathrm{pH}$ value is only slightly above the $\mathrm{pH}_{\text {min }}$ under these conditions, the wild-type strain can grow relatively well at this $\mathrm{pH}$ value and therefore this combination of $\mathrm{pH}$ and time should be suited to select mutants affected in growth at low $\mathrm{pH}$.

Eleven out of the 8544 mutants tested remained below an $\mathrm{OD}_{600}$ of 0.100 after $24 \mathrm{~h}$ incubation in $\mathrm{LB}$ at $\mathrm{pH} 4.50$. Determination of transposon insertion sites revealed six different genes: $m n m E(1 \mathrm{x})$, leuO (5x), apaH (1x), waaC (1x), epmA (1x), and $\operatorname{tat} C(2 \mathrm{x})$. The functions of these genes and the exact position of the transposons are listed in Table 3. In all cases except for leu $\mathrm{O}$, the transposons were inserted into the open reading frame of the corresponding genes. In all five leuO mutants, which were retrieved from independent mutagenesis experiments, the transposon was inserted 26 bp upstream of the leuO open reading frame. Although the transposase used in this study has an altered target specificity, exhibiting a much lower degree of insertion specificity than the wild-type transposase (Kleckner et al., 1991), the occurrence of five inserts at exactly the same insertion site may indicate a so-called hotspot at this position. On the other 

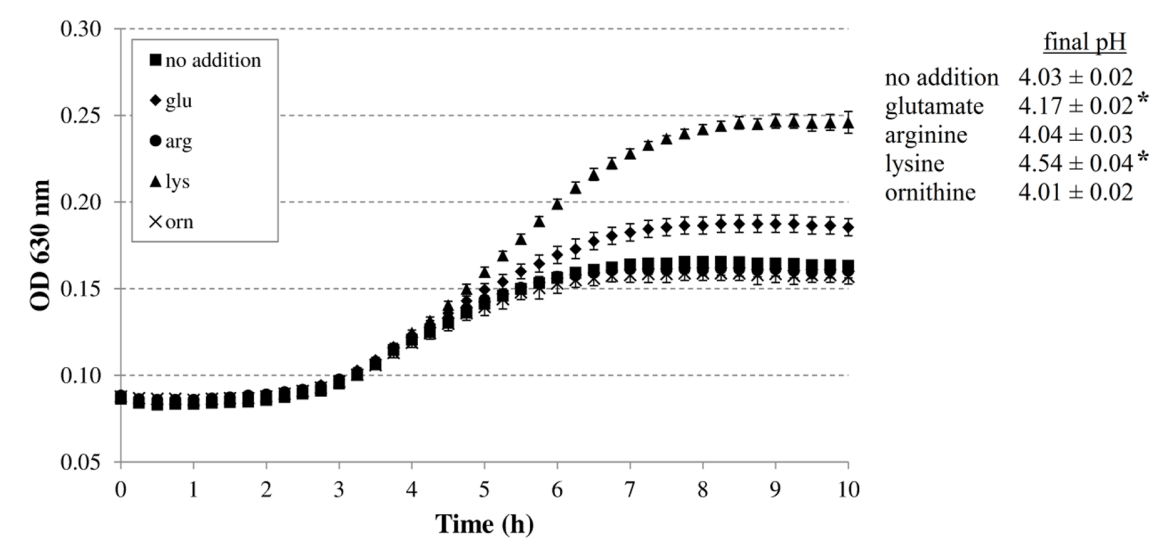

FIGURE 1 | Effect of supplementation with $5 \mathrm{mM}$ glutamate, arginine, lysine, or ornithine on growth of Escherichia coli MG1655 at $37^{\circ} \mathrm{C}$ under anoxic conditions in $\mathbf{M} 9$ medium containing $\mathbf{0 . 2} \%$ glucose, $\mathbf{0 . 1} \%$ casamino acids, and $\mathbf{1} \mathbf{~ m g} / \mathbf{l}$ thiamine. The initial pH of the medium was 4.80 . Error bars represent standard deviations of three replicate cultures. The asterisks indicate when the final $\mathrm{pH}$ value was significantly different $(p<0.05)$ from the final $\mathrm{pH}$ value reached with no specific amino acid addition.

\section{A}
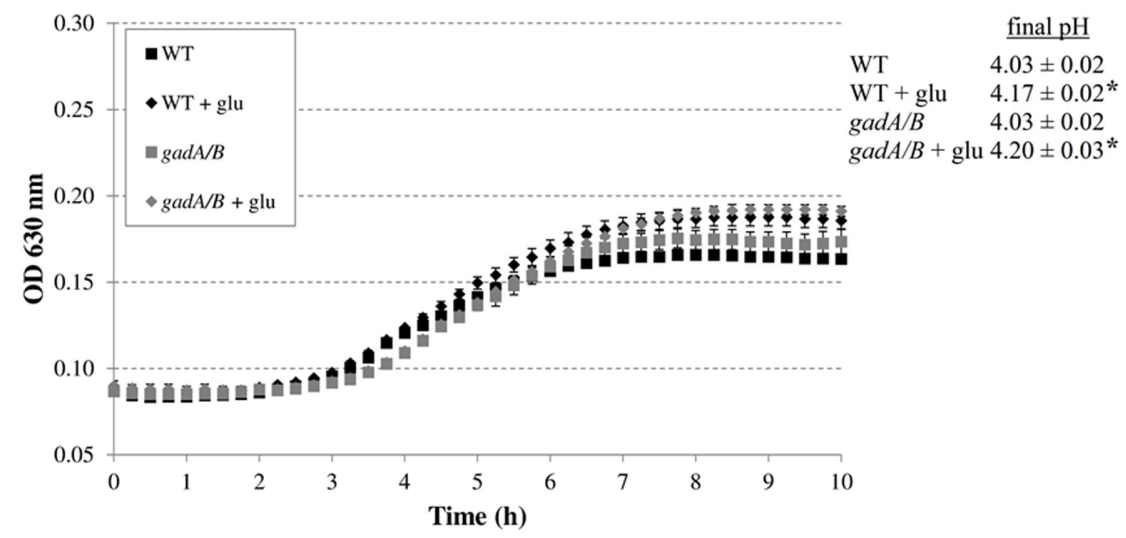

B

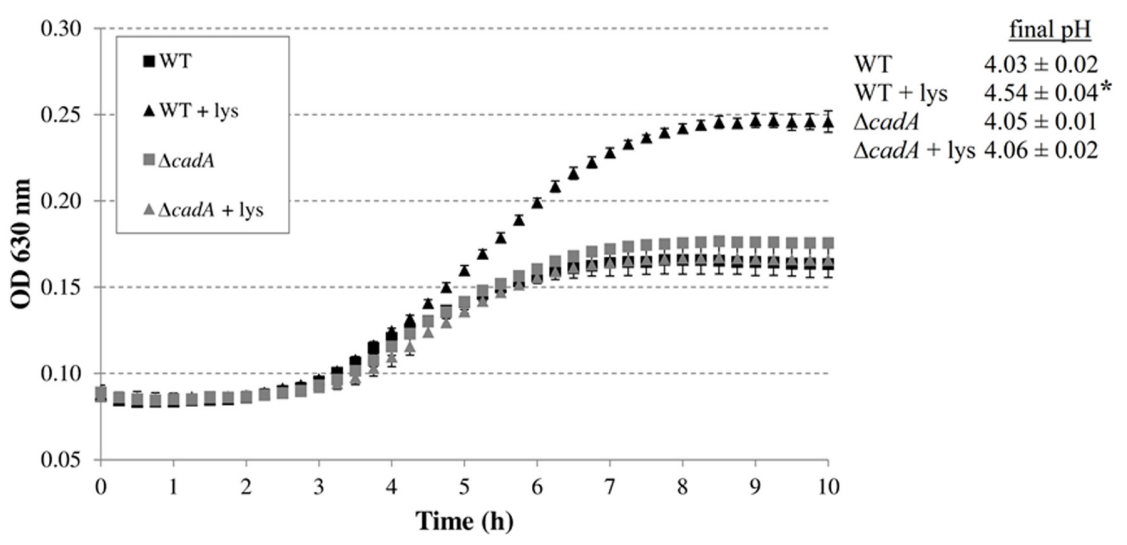

FIGURE 2 | Effect of supplementation with amino acids $(5 \mathrm{mM})$ on growth of decarboxylase-deficient mutants of $E$. coli under anoxic conditions at $37^{\circ} \mathrm{C}$ in $\mathrm{M9}$ medium containing $0.2 \%$ glucose, $0.1 \%$ casamino acids, and $1 \mathrm{mg} / \mathrm{l}$ thiamine, and at an initial pH of 4.80. E. coli MG1655 WT and gadA/B, and supplementation with glutamate (A), and E. coli MG1655 WT and $\Delta$ cadA, and supplementation with lysine (B). The initial pH of the medium was 4.80. Error bars represent standard deviations of three replicate cultures. The asterisks indicate that the final $\mathrm{pH}$ value is significantly different $(p<0.05)$ from the final $\mathrm{pH}$ reached with no specific amino acid addition for the same strain. 


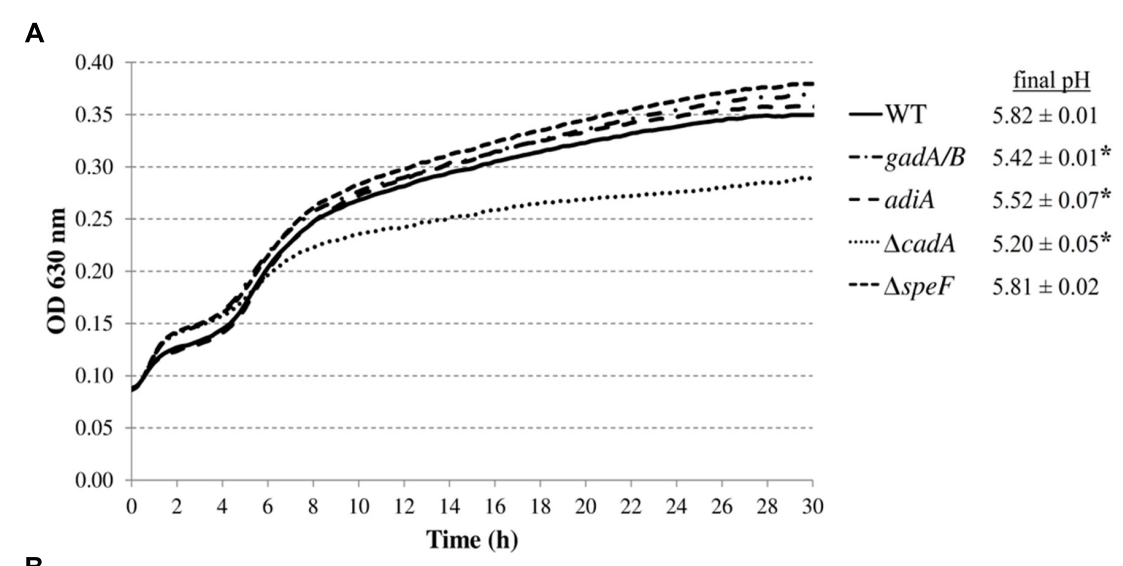

B

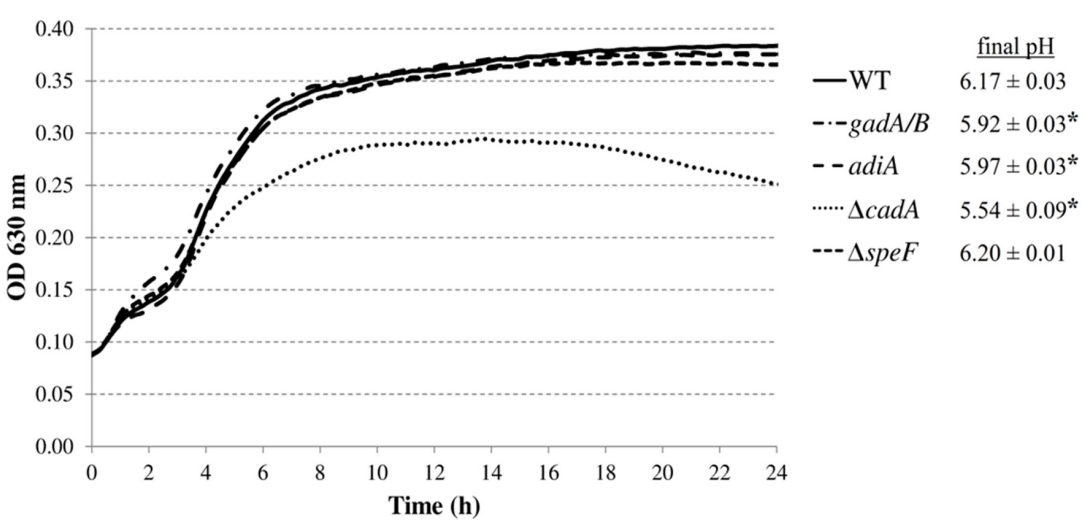

FIGURE 3 | Growth of E. coli MG1655 WT, gadA/B, adiA, $\Delta c a d A$, and $\Delta s p e F$ in LB acidified with $\mathrm{HCl}$ to pH 4.40 (A) or pH 4.60 (B) at $37^{\circ} \mathrm{C}$. Growth curves were averaged across three replicate cultures. The asterisks indicate that the final $\mathrm{pH}$ value is significantly different $(p<0.05)$ from that of the wild-type strain.

TABLE 3 | Overview of genes affected in the transposon insertion mutants of which the growth was impaired in LB pH 4.50.

\begin{tabular}{lcl}
\hline Gene & $\begin{array}{c}\text { Position of } \\
\text { transposon }\end{array}$ & Function \\
\hline$m n m E$ & +820 & $\begin{array}{l}\text { 5-methylaminomethyl-2-thiouridine modification of } \\
\text { tRNA }\end{array}$ \\
leuO* & -26 & DNA-binding transcriptional dual regulator \\
apaH & +614 & Diadenosine tetraphosphatase \\
waaC & +644 & ADP-heptose:LPS heptosyltransferase I \\
epmA & +259 & EF-P-lysine lysyltransferase \\
tatC & $+23 ;$ & Export of folded proteins across the cytoplasmic \\
& +441 & membrane
\end{tabular}

The position of the transposon gives the nucleatide after which the rtansposon was inserted, starting from the first base of the start codon. In the case of leuO, the insertion was 26 bp upstream of the leuO open reading frame.

hand, the two insertions in $\operatorname{tat} C$ were at different positions in the tatC gene.

\section{Construction of Deletion Mutants and Complementation}

To exclude the possibility that these acid-sensitive phenotypes were due to polar genetic effects of the transposon or due to unrelated secondary mutations, de novo deletion mutants were made in E. coli MG1655. However, the tatC mutant was excluded from further analysis, since the $E$. coli K12 chromosome encodes at least 36 polypeptides that are known or predicted substrates for export by the twin-arginine translocation (Tat) system (TatABCE) (Berks et al., 2005), and inactivation of this system probably has pleiotropic effects on the E. coli physiology. The $\mathrm{OD}_{630}$ growth curves of these deletion mutants confirmed their reduced growth in $\mathrm{LB}$ at $\mathrm{pH} 4.50$, except for the $\Delta l e u O$ mutant, which showed WT growth (data not shown). Since the transposon of the originally isolated mutant was inserted 26 bases upstream of the start codon, we assume it did not completely knock out leuO gene function, but may have modified its expression level or regulation. Subsequently, expression constructs derived from the pTrc99A plasmid were made for complementation and introduced into the corresponding deletion mutants (except for leuO). The deletion mutants harboring the empty pTrc99A plasmid or the complementation plasmid were then grown in $\mathrm{LB}$ at $\mathrm{pH} 4.50$ at 30 or $37^{\circ} \mathrm{C}$ (Figure 4), and the $\mathrm{OD}_{630}$ growth curves show that complementation effectively restored moderately low $\mathrm{pH}$ growth to wild-type levels.

Next, growth of the mutants in acidified LB was evaluated in more detail by determining plate counts and medium $\mathrm{pH}$ every 
A

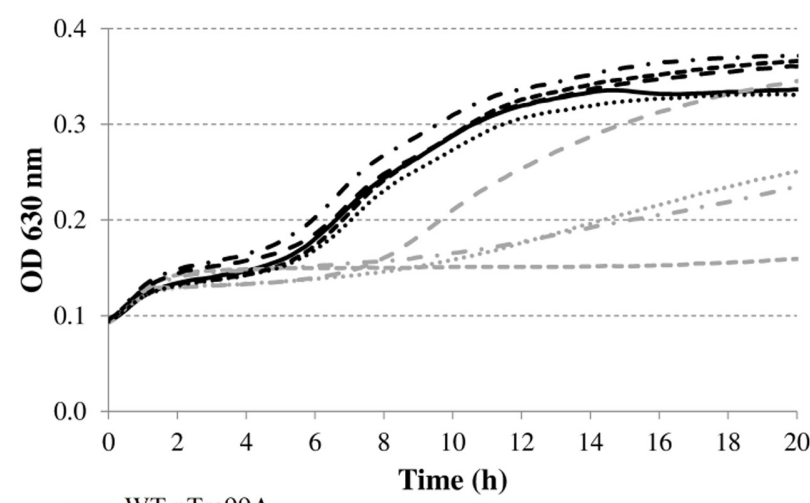

- WT pTrc99A

$----\triangle a p a H \mathrm{p} T \mathrm{rc} 99 \mathrm{~A}$

$-\cdot-\Delta e p m A \mathrm{p} T \mathrm{rc} 99 \mathrm{~A}$

---- $\triangle a p a H$ pTrc99A-P

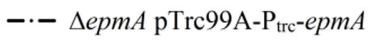

\section{B}

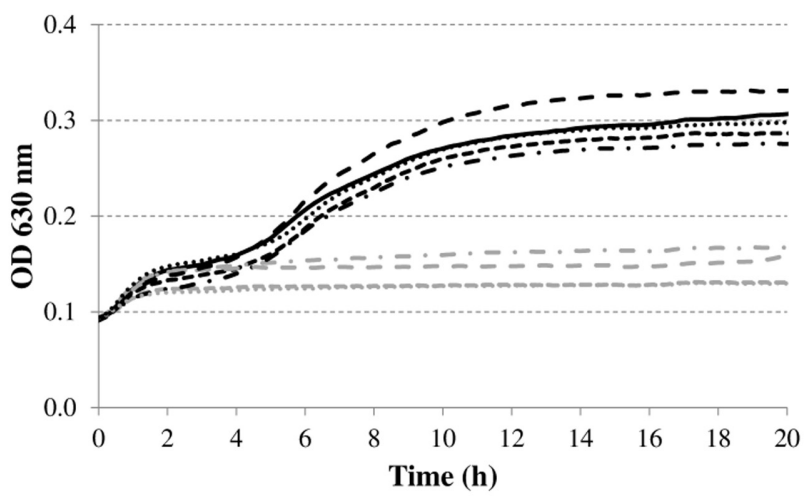

- - $\Delta$ waaC pTrc99A

… $\triangle m n m E$ pTrc99A

- - $\Delta$ waaC pTrc99A-P trc waaC

FIGURE 4 | Growth of E. coli MG1655 WT containing pTrc99A, deletion mutants containing pTrc99A, and deletion mutants containing complementation plasmids in $\mathrm{LB} \mathrm{pH} 4.50$ at $30^{\circ} \mathrm{C}$ (A) or $37^{\circ} \mathrm{C}$ (B). Growth curves were averaged across three replicate cultures.

$3 \mathrm{~h}$ (Figure 5). The growth parameter estimates for the initial $\left(y_{0}\right)$ and final $\left(y_{\max }\right)$ bacterial cell density, the maximum specific growth rate $\left(\mu_{\max }\right)$, and the lag time $\left(t_{\text {lag }}\right)$ are shown in Table 4.

The results show that the cell numbers and the $\mathrm{pH}$ values for the wild-type and the $\Delta l e u O$ mutant evolved in a similar way, and that the growth parameters for both strains were not significantly different. The $\triangle a p a H$ mutant was not able to grow at this $\mathrm{pH}$ (as already evident from Figure 4) and its cell numbers decreased slightly, reaching around $3.1 \log (\mathrm{cfu} / \mathrm{ml})$ after $48 \mathrm{~h}$. The remaining three mutants had a significantly slower growth rate $\left(\mu_{\max }\right)$, and, in addition, the $\triangle m n m E$ and $\triangle e p m A$ mutants had slightly lower maximal cell densities $\left(y_{\max }\right)$, while the $\triangle w a a C$ and $\triangle m n m E$ mutants exhibited a significantly longer lag phase $\left(t_{\text {lag }}\right)$ than the wild-type (Table 4). Interestingly, all strains that initiated growth did so without increasing medium $\mathrm{pH}$ initially. Only when cell numbers exceeded around 7.0 $\log (\mathrm{cfu} / \mathrm{ml})$, medium $\mathrm{pH}$ started increasing until early stationary phase. The maximum $\mathrm{pH}$ value reached by all strains that started growing, except for the $\Delta m n m E$ mutant, was around 5.10 and this $\mathrm{pH}$ value remained unchanged during stationary phase (Figure 5).

\section{Growth of Mutants in Acidic Foods}

In a subsequent step, we investigated growth of the deletion mutants (except the $\Delta l e u O$ mutant) in apple juice ( $\mathrm{pH} 4.60)$ and tomato juice ( $\mathrm{pH} 4.80$ ) (Figure 6). While previous experiments in $\mathrm{LB}$ were conducted at 30 or $37^{\circ} \mathrm{C}$, the experiments in juice were done at $20^{\circ} \mathrm{C}$ to simulate possible food storage conditions. All the mutants also showed growth defects in these acidic foods but the nature and relative magnitude of the defects was different in these foods than in acidified LB (Figure 5) for some mutants. For example, while the $\Delta w a a C$ mutant showed an extended lag phase in acidified LB and the $\triangle e p m A$ mutant did not, this was reversed in the juices. Another example is the $\triangle m n m E$ mutant, which was able to grow in acidified LB but was slowly inactivated in the juices. The $\triangle a p a H$ mutant showed similar behavior in acidified LB and in the juices, being inactivated in all situations. Also in contrast to growth in acidified LB, bacterial growth in acidic juices did not result in an extracellular $\mathrm{pH}$ increase. Instead, the juice $\mathrm{pH}$ remained almost constant (maximal variation was 0.04 $\mathrm{pH}$ units) for all strains during the entire experiment (data not shown).

\section{Survival of Mutants in Acid Challenge Assay in Simulated Gastric Fluid}

Finally, we investigated whether the mutations rendered E. coli MG1655 also more sensitive to inactivation at extremely low $\mathrm{pH}$. Therefore, the AR of the deletion mutants was examined in a simulated gastric fluid $(\mathrm{pH} 2.50)$ at $37^{\circ} \mathrm{C}$ (Figure 7 ). The survival data were fitted and $D$-values were calculated from the linear part. All curves, except that of the $\Delta$ waaC mutant, displayed a shoulder before a substantial decrease was apparent. Unexpectedly, the $\Delta e p m A$ and $\Delta w a a C$ mutants were more acid resistant than the wild-type strain, showing significantly higher D-values under these conditions, while the other genes did not influence survival of E. coli MG1655 in the simulated gastric fluid.

\section{DISCUSSION}

\section{Amino Acid Decarboxylase Systems}

The best described AR mechanisms in Enterobacteriaceae rely on proton consumption during amino acid decarboxylation. In E. coli, four AR systems (AR 2, 3, 4, and 5) have been described in which a particular amino acid (glutamate, arginine, lysine, or ornithine, respectively) is converted to its corresponding amine (GABA, agmatine, cadaverine, or putrescine, respectively) by a cytoplasmic decarboxylase (the GadA and GadB isozymes, AdiA, 
A

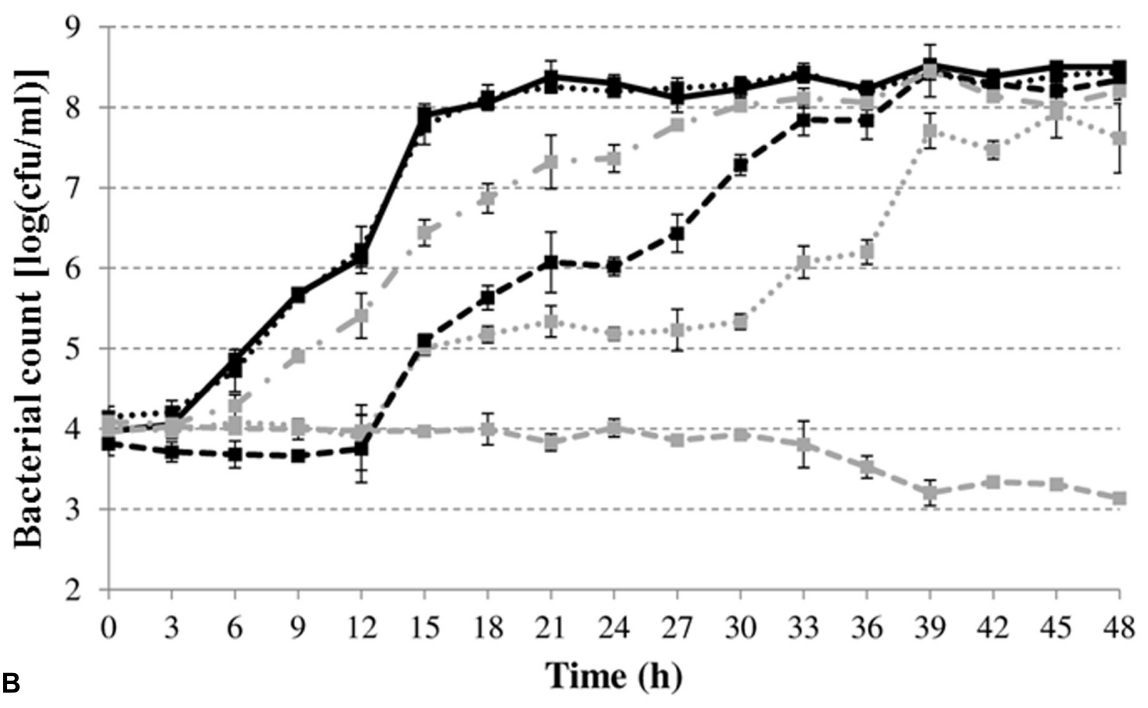

Time (h)

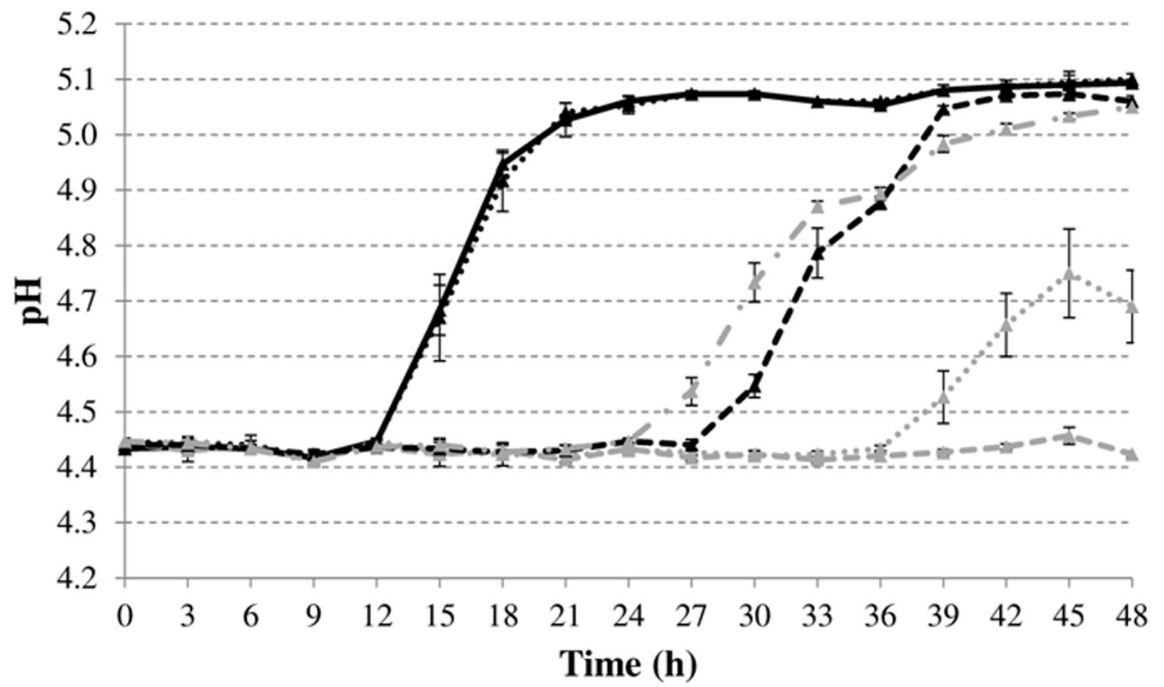

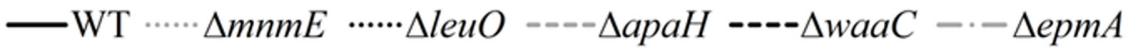

FIGURE 5 | Cell numbers (A) and pH values (B) during growth of $E$. coli MG1655 WT and deletion mutants in LB pH 4.40 at $30^{\circ} \mathrm{C}$. Error bars represent standard deviations for three independent replicates. The corresponding growth parameters are shown in Table 4.

TABLE 4 | Parameter estimates for the initial $\left(y_{0}\right)$ and final $\left(y_{\max }\right)$ bacterial cell density, the maximum specific growth rate $\left(\mu_{\text {max }}\right)$, and the lag time $\left(t_{\text {lag }}\right)$ during growth of E. coli MG1655 WT and deletion mutants in acidified LB (initial pH around 4.4 ) at $30^{\circ} \mathrm{C}$ for $48 \mathrm{~h}$ (growth curves in Figure 4).

\begin{tabular}{|c|c|c|c|c|c|}
\hline Growth parameter & WT & $\Delta m n m E$ & $\Delta / e u O$ & $\Delta$ waaC & $\Delta e p m A$ \\
\hline$y_{0}$ & $3.95 \pm 0.06$ & $4.02 \pm 0.08$ & $4.15 \pm 0.16$ & $3.62 \pm 0.05^{*}$ & $3.98 \pm 0.07$ \\
\hline$y_{\max }$ & $8.36 \pm 0.03$ & $7.93 \pm 0.05^{*}$ & $8.32 \pm 0.02$ & $8.33 \pm 0.09$ & $8.12 \pm 0.10^{*}$ \\
\hline$\mu_{\max }$ & $0.76 \pm 0.06$ & $0.26 \pm 0.02 *$ & $0.80 \pm 0.06$ & $0.40 \pm 0.02^{*}$ & $0.47 \pm 0.05^{*}$ \\
\hline$t_{\operatorname{lag}}$ & $3.92 \pm 0.61$ & $12.76 \pm 1.67^{*}$ & $5.00 \pm 1.20$ & $8.82 \pm 1.03^{*}$ & $4.50 \pm 0.73$ \\
\hline
\end{tabular}

Values are means \pm standard deviations $(n=3)$. The asterisks indicate that the parameter value is significantly different $(p<0.05)$ from that of the wild-type strain.

CadA, and SpeF, respectively), followed by the exchange of the decarboxylated products for new amino acid substrates via a cognate inner membrane-bound antiporter (GadC, AdiC, CadB, and PotE, respectively) (Zhao and Houry, 2010). The strength of these systems to protect against extreme acid stress has been correlated to the $\mathrm{pH}$ optima of the decarboxylase enzymes, being 3.7-3.8, 4.9-5.2, 5.7, and 7.0, respectively (Kanjee and Houry, 2013). Thus, the glutamate-dependent AR system is the most 

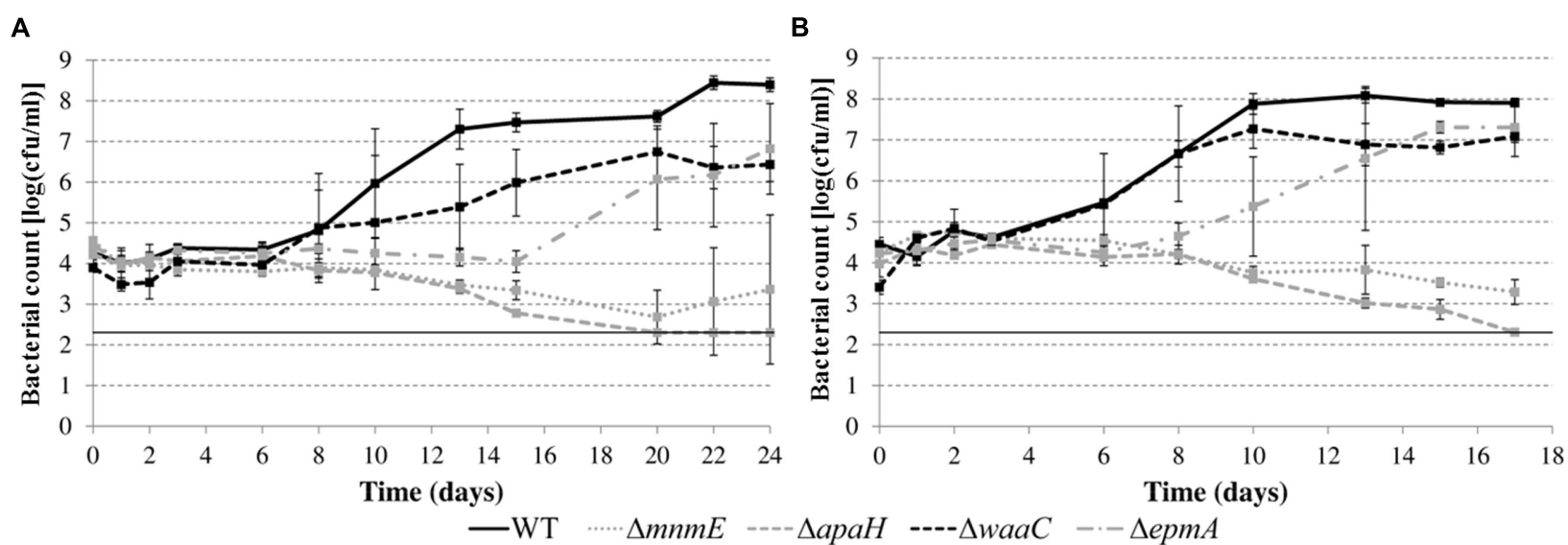

FIGURE 6 | Growth of E. coli MG1655 WT and deletion mutants in apple juice pH 4.60 (A) and tomato juice pH 4.80 (B) at $20^{\circ} \mathrm{C}$. Error bars represent standard deviations of three indemendent replicate cultures. The line at $2.3 \log (\mathrm{cfu} / \mathrm{ml})$ represents the lower detection limit.

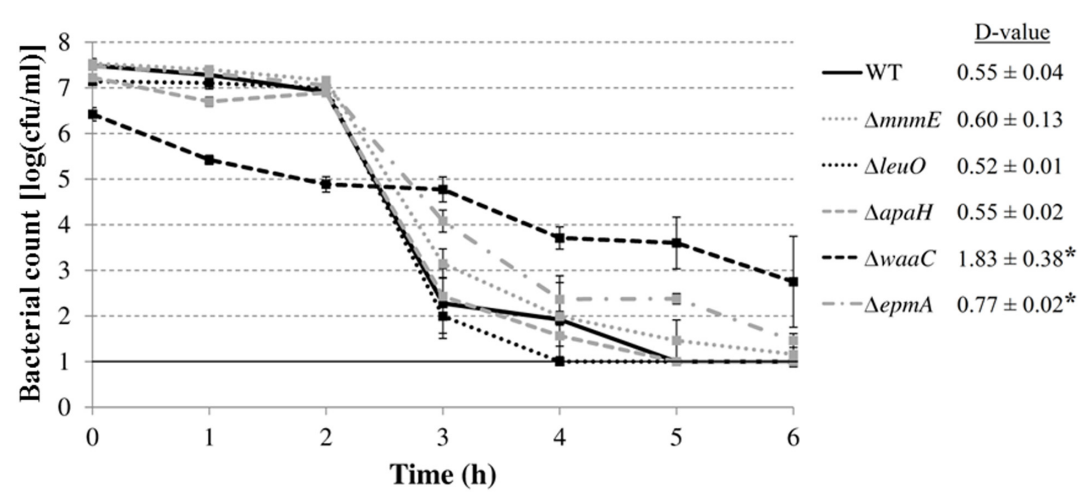

FIGURE 7 | Survival of E. coli MG1655 WT and deletion mutants at $37^{\circ} \mathbf{C}$ in simulated gastric fluid pH 2.50. Error bars represent standard deviations of three independent replicate experiments. The line at $1.0 \mathrm{log}(\mathrm{cfu} / \mathrm{ml})$ represents the detection limit. $D$-values (in $\mathrm{h}$ ) are shown next to the figure and are expressed as means \pm standard deviations. Asterisks indicate significant differences $(p<0.05)$ with the wild-type strain.

potent AR system in E. coli, followed by the arginine- and lysinedependent AR systems (Iyer et al., 2003; Diez-Gonzalez and Karaibrahimoglu, 2004). The ornithine-dependent AR system has been less well studied and plays only a minor role during survival of an extreme acid challenge. For example, in E. coli, only glutamate, arginine, and lysine, but not ornithine, supported robust survival at $\mathrm{pH} 2.5$ in a minimal medium (Iyer et al., 2003). Also survival of Salmonella was only modestly improved by ornithine in a minimal medium at pH 2.3 (Viala et al., 2011).

In our study, the ability of these systems to enhance growth under moderate acid stress was investigated. We showed that only lysine considerably improved growth of E. coli MG1655 at moderately low $\mathrm{pH}$ in a minimal medium, and that this effect relies on lysine decarboxylation since it was not observed in a $\Delta c a d A$ mutant (Figures 1 and 2). Similarly, only the lysine decarboxylase CadA enhanced growth of E. coli MG1655 at moderately low pH in a complex medium (Figure 3). Although also the glutamate decarboxylase isozymes GadA and GadB and the arginine decarboxylase AdiA provoked a slight $\mathrm{pH}$ increase during growth in complex medium at moderately low $\mathrm{pH}$, this effect was insufficient to confer a growth advantage. The relative effectiveness of these decarboxylases to support low $\mathrm{pH}$ growth may reflect their $\mathrm{pH}$ optima. Since $E$. coli cannot maintain an internal $\mathrm{pH}$ of more than two units higher than the external $\mathrm{pH}$ (Foster, 2004), the internal $\mathrm{pH}$ during growth at an external $\mathrm{pH}$ of 4.5 is expected to be around 6.5, which is close to the $\mathrm{pH}$ optimum of 5.7 of CadA. However, other factors are also involved, since the ornithine decarboxylase SpeF ( $\mathrm{pH}$ optimum 7.0) did not contribute to growth under these conditions. This is in contrast to Salmonella, in which both lysine and ornithine decarboxylases significantly improved growth at moderately acidic $\mathrm{pH}$ under anoxic conditions in a minimal medium supplemented with these amino acids (Viala et al., 2011).

A mutant that can be indirectly linked to the lysine decarboxylase system is the mutant which had the transposon inserted just $26 \mathrm{bp}$ upstream of the leuO open reading frame, leaving the putative ribosomal binding site fully intact. Remarkably, insertion of a Tn10 transposon at exactly the same site has been reported previously, and was shown to result in overexpression of LeuO (Klauck et al., 1997). This might also 
be the case in our study since deletion of leuO did not affect the growth of E. coli MG1655 at moderately low $\mathrm{pH}$. Moreover, it has been shown that LeuO overexpression drastically reduces production of CadC, the essential activator for cadA induction (Shi and Bennett, 1995), and this might explain its role in growth at low $\mathrm{pH}$. Furthermore, LeuO has also indirectly been linked to AR since it represses the small non-coding RNA $d s r A$, which plays a regulatory role in AR in E. coli (Lease et al., 2004). Finally, also the epmA gene, discussed in the next section, can be linked to CadA activity.

In conclusion, our results show that the decarboxylase enzymes not only produce better survival at extremely low $\mathrm{pH}$ by counteracting intracellular acidification (Richard and Foster, 2004), they also trigger deacidification of the extracellular medium, thereby potentially enhancing growth at moderately low $\mathrm{pH}$.

\section{Aminoacyl-tRNA Synthetases and Translation Elongation}

The mutant with the strongest growth defect at low $\mathrm{pH}$ was an $a p a H$ mutant. This mutant was not able to grow in $\mathrm{LB}$ at $\mathrm{pH}$ 4.50 , while its growth rate was only slightly less than that of the wild-type at neutral $\mathrm{pH}$ (data not shown). The apaH gene encodes diadenosine tetraphosphatase, which hydrolyzes 5,5"'$\mathrm{P}^{1}, \mathrm{P}^{4}$-diadenosine tetraphosphate (AppppA) to two molecules of adenosine diphosphate (ADP) (Guranowski et al., 1983). AppppA is rapidly synthesized by aminoacyl-tRNA synthetases when E. coli is exposed to heat shock or oxidative stress and may serve as a modulator of these stress responses (Johnstone and Farr, 1991). It has been shown that apaH mutants, which have high basal levels of AppppA, are sensitive to killing by heat and oxidative stress, and are unable to grow at $43^{\circ} \mathrm{C}$ (Johnstone and Farr, 1991). AppppA binds to several proteins in E. coli, including DnaK, GroEL, and $\mathrm{ClpB}$, and AppppA binding may inhibit DnaK and/or GroEL functions that are required for survival of thermal stress. Thus, the regulation of the AppppA pool is important for the bacterial response to conditions of stress and AppppA may assist the return of cells to normal growth conditions following stress, but constitutively high levels of AppppA may inhibit the function of stress proteins such as DnaK before they have fulfilled their role under that stress (Johnstone and Farr, 1991; McLennan et al., 2001). Our results suggest that AppppA is also involved in cellular adaptation to acid stress. Since the cytoplasmic chaperones DnaK and GroEL have also been linked to counteracting acid stress in several bacteria, such as $S$. enterica and $H$. pylori, a similar mechanism may also account for the role of AppppA under acid stress (Bearson et al., 2006).

Another protein that was found in our work to play a role during growth at low $\mathrm{pH}$ was EpmA. EpmA specifically aminoacylates the translation elongation factor $\mathrm{P}$ (EF-P) at a conserved lysine residue with $\beta$-lysine. This posttranslational modification activates EF-P to function in translation elongation of a particular subset of mRNAs (Bullwinkle et al., 2013). It has been demonstrated that EF-P enhances the translation of polyproline-containing proteins by alleviating ribosome stalling at polyproline stretches (Ude et al., 2013). One such protein is CadC, a membrane-integrated transcriptional regulator that both senses external $\mathrm{pH}$ and activates expression of the cadBA operon at low external pH. EF-P was shown to be required for translation of CadC and a deletion mutant of epmA lacked CadA activity (Ude et al., 2013), which may account for the diminished growth at moderately low $\mathrm{pH}$ in our experiments. Interestingly, EpmA is an aminoacyl-tRNA synthetase paralog, showing sequence similarity to the lysyl-tRNA synthetases LysS and LysU. Whereas LysS is constitutively expressed, LysU is overexpressed under extreme physiological conditions, such as heat shock, and is the most effective AppppA synthetase, producing $80 \%$ of total AppppA in E. coli cell extracts (Charlier and Sanchez, 1987). In addition to high temperature, LysU has also been shown to be upregulated at moderately low $\mathrm{pH}$ (Hayes et al., 2006). Interestingly, the activity of LysU has been shown to be less sensitive than that of LysS to the competitive inhibitor cadaverine, the decarboxylation product of lysine, suggesting that LysU plays a more important role under physiological conditions causing cadaverine accumulation, such as acid stress (Brevet et al., 1995). Although EpmA is homologous to the catalytic core of the lysyl-tRNA synthetases, it lacks the tRNA aminoacylation activity due to absence of the tRNA anticodon-binding domain. Nevertheless, EpmA retains the ability to activate L-lysine by formation of the lysyl-adenylate intermediate (Ambrogelly et al., 2010), which is also the first step in AppppA synthesis. However, it is not known whether EpmA can also contribute to AppppA production.

The screening also yielded a gene that is involved in tRNA modification, mnmE. Together with MnmG, MnmE forms a complex that adds an aminomethyl or carboxymethylaminomethyl group to position 5 of the anticodon wobble uridine $\left(\mathrm{U}_{34}\right)$ using methylene-tetrahydrofolate and ammonium or glycine as donors, respectively (Moukadiri et al., 2014). Approximately 85 different modifications of tRNA molecules have been documented, and they are thought to be important for maintaining tRNA structure, and for specific recognition of tRNA molecules by their cognate aminoacyl-tRNA synthetases. Besides, the idea that tRNA modifications can take on second-order regulatory functions, especially in response to stress conditions, has recently emerged. Some recent studies have linked tRNA modification to the control of gene expression at the level of translation in response to environmental stresses. For example, Begley et al. (2007) have shown that the tRNA methyltransferase 9 (Trm9) of Saccharomyces cerevisiae, which catalyzes the last step (methylation) in the methylcarbonylmethyl $(\mathrm{mcm})$ modification on position 5 of the uridine wobble base $\left(\mathrm{U}_{34}\right)$ of tRNA ${ }^{\mathrm{Arg}}{ }_{\mathrm{mcm} 5 \mathrm{UCU}}$ and tRNA ${ }^{\mathrm{Glu}}{ }_{\mathrm{mcm} 5 \mathrm{~s} 2 \mathrm{UUC}}$, prevents cell death during methyl methanesulfonate exposure via translational enhancement of DNA damage response proteins whose genes are overrepresented with the AGA (Arg) and GAA (Glu) codons. This indicates that tRNA modifications indirectly help coordinate DNA repair. Also in S. cerevisiae, it has been demonstrated that the modifications 2'-O-methylcytosine $(\mathrm{Cm})$, 5-methylcytosine $\left(\mathrm{m}^{5} \mathrm{C}\right)$, and $N^{2}, N^{2}$-dimethylguanosine $\left(\mathrm{m}^{2}{ }_{2} \mathrm{G}\right)$ increase following exposure to hydrogen peroxide and that loss of the methyltransferase enzymes catalyzing the formation of these modified nucleosides causes hypersensitivity to hydrogen peroxide (Chan et al., 2010). Thus, tRNA modifications 
can dynamically change in response to stress and may be critical features of the cellular stress response. Furthermore, exposing $S$. cerevisiae to hydrogen peroxide resulted in a Trm 4 methyltransferase-dependent increase in the incorporation of $\mathrm{m}^{5} \mathrm{C}$ in tRNA ${ }_{\mathrm{m}}^{\mathrm{Leu}}$ CAA, which causes selective translation of mRNA from genes that are enriched in the TTG codon for leucine (Chan et al., 2012). Cells may thus respond and adapt to environmental stresses by reprogramming of tRNA modifications, thereby promoting the selective translation of codon-biased mRNAs for critical stress response proteins (Dedon and Begley, 2014). Our work extends these observations by linking t-RNA modification by $\mathrm{MnmE}$ to growth at low $\mathrm{pH}$ in E. coli.

\section{Cell Envelope}

The waaC gene which was picked up in our screening is involved in the synthesis of lipolpolysaccharide (LPS). WaaC adds ADP-L-glycero-D-manno-heptose on the inner 3-deoxy-Dmanno-octulosonic acid (KDO) residue of the LPS inner core with the release of ADP (Kadrmas and Raetz, 1998). Knockout of waaC results in a heptoseless truncation of the LPS and a so-called deep-rough phenotype, characterized by mucoid colonies phenotype due to production of a colanic acid capsular polysaccharide (Joloba et al., 2004). This phenotype was clearly visible when these mutants were grown on agar plates in our experiments. The production of this polysaccharide might also be the reason for their higher final OD values compared to the wild-type in some growth experiments (Figure 4B). Bielecki et al. (1982) used chemical mutagenesis to isolate mutants of E. coli K12 that were not able to grow on LB agar plates acidified with $\mathrm{HCl}$ to $\mathrm{pH}$ 5.4. Four mutants were picked up and a number of altered phenotypes (phage and detergent sensitivities, leakage of periplasmic proteins) suggested that these mutants probably belonged to a group of deep-rough mutants defective in their LPS. Thus, the capacity of the outer membrane to form a proton barrier is probably reduced by lesions in the LPS structure (Rowbury, 2004). Furthermore, Barua et al. (2002) isolated five transposon insertion mutants of E. coli O157:H7 that showed poor or no growth on LB-MES agar with $12 \mathrm{mM}$ acetic acid $(\mathrm{pH} 5.4)$. Two of them had an inactivated waaG gene, also causing a deep-rough phenotype. The other three genes $(f c l$, $w e c A$, and $w e c B$ ) were involved in the biosynthesis of the surface $O$-polysaccharide and/or enterobacterial common antigen.

Interestingly, a waaC mutant has been shown to be unable to express the outer membrane protein A (OmpA) (Beher and Schnaitman, 1981). OmpA is one of the most abundant proteins in the outer membrane of $E$. coli and is believed to be a nonspecific diffusion channel, allowing the passage of various small solutes, but its physiological function is unclear. OmpA is induced by acid in E. coli and has previously been linked with AR in $E$. coli since an ompA mutant was more readily killed by lethal acid stress ( $\mathrm{pH} 3.8 ; 60 \mathrm{mM}$ acetic acid) than its parent strain (Wang, 2002). OmpA is also important for the structural integrity of the cell envelope, and loss of OmpA probably leads to increased penetration of protons or undissociated acids through the outer membrane due to reduced barrier properties (Rowbury, 2004).

\section{Efficiency of Mutant Screening}

The discussion above suggests that besides the six mutants isolated in this work, several additional mutants are predicted to have a low $\mathrm{pH}$ growth phenotype, like cadA, cadC, ompA, $m n m G, f c l$, wecA, wecB. Assuming random transposition of the mini-Tn10 transposon, the probability $P$ that the library contains at least one insertion in each (non-essential) gene can be calculated from $N=\ln (1-P) / \ln (1-\mathrm{a} / \mathrm{b})$, with $N=$ number of mutants in the library, $a=$ average size of a gene (1000 bp), and $b=$ genome size (excluding all essential genes). For our library of 8544 mutants, this gives a probability of $86 \%$ that any particular non-essential gene is represented. It seems therefore that the screen picked up less mutants than would be expected. This may be partly explained by non-randomness of the tranposon and the fact that inserts in the $3^{\prime}$ end of a gene do not necessarily knock out protein function. However, probably a more important explanation is that threshold set for isolation of mutants $\left(\mathrm{OD}_{600}<0.100\right.$ after $24 \mathrm{~h}$ incubation in $\mathrm{LB}$ at $\mathrm{pH}$ 4.50) filtered out only the most sensitive mutants. A screen based on recording full growth curves (as opposed to end point measurement) would most likely reveal additional, more subtle mutations.

\section{CONCLUSION}

By identifying genes required for growth at moderately low $\mathrm{pH}$, this work has yielded new insights in the cellular mechanisms used in $E$. coli to cope with mild acid stress. The lysine decarboxylase system, but not other amino acid decarboxylases known to contribute to survival of extreme acid stress, was demonstrated to support growth at moderately low $\mathrm{pH}$. In line with previous findings, the integrity of the outer membrane was also shown to be important for growth at low $\mathrm{pH}$. In addition, tRNA modification and diadenosine tetraphosphate hydrolysis were identified for the first time to be required for low $\mathrm{pH}$ growth. Except for the lysine decarboxylase, the cellular functions supporting low $\mathrm{pH}$ growth did not support survival of extreme low $\mathrm{pH}$. This work will contribute to a better understanding of microbial survival and growth in mildly acidic foods.

\section{AUTHOR CONTRIBUTIONS}

CM: Conception of research project, research strategy, interpretation of results, final stages of writing of manuscript. BV: Research strategy, experimental work, interpretation of results, writing of manuscript. AA: Conception of research project, research strategy, interpretation of results

\section{FUNDING}

This work was supported by research grants from the Fonds voor Wetenschappelijk Onderzoek Vlaanderen (G.A061.11) and the Research Council of KU Leuven (METH/14/03). Author BV was the recipient of a doctoral fellowship from the Agentschap voor Innovatie door Wetenschap en Technologie (IWT). 


\section{REFERENCES}

Alegre, I., Abadias, M., Anguera, M., Oliveira, M., and Viñas, I. (2010). Factors affecting growth of foodborne pathogens on minimally processed apples. Food Microbiol. 27, 70-76. doi: 10.1016/j.fm.2009.08.005

Álvarez-Ordóñez, A., Prieto, M., Bernardo, A., Hill, C., and López, M. (2012). The acid tolerance response of Salmonella spp.: an adaptive strategy to survive in stressful environments prevailing in foods and the host. Food Res. Int. 45, 482-492. doi: 10.1016/j.foodres.2011.04.002

Amann, E., Ochs, B., and Abel, K.-J. (1988). Tightly regulated tac promoter vectors useful for the expression of unfused and fused proteins in Escherichia coli. Gene 69, 301-315. doi: 10.1016/0378-1119(88)90440-4

Ambrogelly, A., O’Donoghue, P., Söll, D., and Moses, S. (2010). A bacterial ortholog of class II lysyl-tRNA synthetase activates lysine. FEBS Lett. 584, 3055-3060. doi: 10.1016/j.febslet.2010.05.036

Baba, T., Ara, T., Hasegawa, M., Takai, Y., Okumura, Y., Baba, M., et al. (2006). Construction of Escherichia coli K-12 in-frame, single-gene knockout mutants: the Keio collection. Mol. Syst. Biol. 2, 2006.0008. doi: 10.1038/msb4100050

Baka, M., Van Derlinden, E., Boons, K., Mertens, L., and Van Impe, J. F. (2013). Impact of $\mathrm{pH}$ on the cardinal temperatures of E. coli K12: evaluation of the gamma hypothesis. Food Control 29, 328-335. doi: 10.1016/j.foodcont.2012.04.022

Baranyi, J., and Roberts, T. A. (1994). A dynamic approach to predicting bacterial growth in food. Int. J. Food Microbiol. 23, 277-294. doi: 10.1016/01681605(94)90157-0

Barua, S., Yamashino, T., Hasegawa, T., Yokoyama, K., Torii, K., and Ohta, M. (2002). Involvement of surface polysaccharides in the organic acid resistance of Shiga Toxin-producing Escherichia coli O157:H7. Mol. Microbiol. 43, 629-640. doi: 10.1046/j.1365-2958.2002.02768.x

Beales, N. (2004). Adaptation of microorganisms to cold temperatures, weak acid preservatives, low pH, and osmotic stress: a review. Compr. Rev. Food Sci. Food Saf. 3, 1-20. doi: 10.1111/j.1541-4337.2004.tb00057.x

Bearson, S. M. D., Bearson, B. L., and Rasmussen, M. A. (2006). Identification of Salmonella enterica serovar Typhimurium genes important for survival in the swine gastric environment. Appl. Environ. Microbiol. 72, 2829-2836. doi: 10.1128/AEM.72.4.2829-2836.2006

Begley, U., Dyavaiah, M., Patil, A., Rooney, J. P., DiRenzo, D., Young, C. M., et al. (2007). Trm9-catalyzed tRNA modifications link translation to the DNA damage response. Mol. Cell 28, 860-870. doi: 10.1016/j.molcel.2007.09.021

Beher, M. G., and Schnaitman, C. A. (1981). Regulation of the OmpA outer membrane protein of Escherichia coli. J. Bacteriol. 147, 972-985.

Berks, B. C., Palmer, T., and Sargent, F. (2005). Protein targeting by the bacterial twin-arginine translocation (Tat) pathway. Curr. Opin. Microbiol. 8, 174-181. doi: 10.1016/j.mib.2005.02.010

Beumer, R. R., de Vries, J., and Rombouts, F. M. (1992). Campylobacter jejuni nonculturable coccoid cells. Int. J. Food Microbiol. 15, 153-163. doi: 10.1016/01681605(92)90144-R

Bielecki, J., Hrebenda, J., and Kwiatkowski, Z. (1982). Mutants of Escherichia coli K12 sensitive to acidic pH. J. Gen. Microbiol. 128, 1731-1733.

Brevet, A., Chen, J., Lévêque, F., Blanquet, S., and Plateau, P. (1995). Comparison of the enzymatic properties of the two Escherichia coli lysyl-tRNA synthetase species. J. Biol. Chem. 270, 14439-14444. doi: 10.1074/jbc.270.24. 14439

Bullwinkle, T. J., Zou, S. B., Rajkovic, A., Hersch, S. J., Elgamal, S., Robinson, N., et al. (2013). (R)- $\beta$-lysine-modified elongation factor P functions in translation elongation. J. Biol. Chem. 288, 4416-4423. doi: 10.1074/jbc.M112. 438879

Castanie-Cornet, M. P., Penfound, T. A., Smith, D., Elliott, J. F., and Foster, J. W. (1999). Control of acid resistance in Escherichia coli. J. Bacteriol. 181, 3525-3535.

Chan, C. T. Y., Dyavaiah, M., DeMott, M. S., Taghizadeh, K., Dedon, P. C., and Begley, T. J. (2010). A quantitative systems approach reveals dynamic control of tRNA modifications during cellular stress. PLOS Genet. 6:e1001247. doi: 10.1371/journal.pgen.1001247

Chan, C. T. Y., Pang, Y. L. J., Deng, W., Babu, I. R., Dyavaiah, M., Begley, T. J., et al. (2012). Reprogramming of tRNA modifications controls the oxidative stress response by codon-biased translation of proteins. Nat. Commun. 3:937. doi: $10.1038 /$ ncomms 1938
Charlier, J., and Sanchez, R. (1987). Lysyl-tRNA synthetase from Escherichia coli K12. Biochem. J. 248, 43-51. doi: 10.1042/bj2480043

Datsenko, K. A., and Wanner, B. L. (2000). One-step inactivation of chromosomal genes in Escherichia coli K-12 using PCR products. Proc. Natl. Acad. Sci. U.S.A. 97, 6640-6645. doi: 10.1073/pnas.120163297

Dedon, P. C., and Begley, T. J. (2014). A system of RNA modifications and biased codon use controls cellular stress response at the level of translation. Chem. Res. Toxicol. 27, 330-337. doi: 10.1021/tx400438d

Dela Vega, A. L., and Delcour, A. H. (1996). Polyamines decrease Escherichia coli outer membrane permeability. J. Bacteriol. 178, 3715-3721.

Diez-Gonzalez, F., and Karaibrahimoglu, Y. (2004). Comparison of the glutamate, arginine- and lysine-dependent acid resistance systems in Escherichia coli O157:H7. J. Appl. Microbiol. 96, 1237-1244. doi: 10.1111/j.13652672.2004.02251.x

Foster, J. W. (2004). Escherichia coli acid resistance: tales of an amateur acidophile. Nat. Rev. Microbiol. 2, 898-907. doi: 10.1038/nrmicro1021

Geeraerd, A. H., Valdramidis, V. P., and Van Impe, J. F. (2005). GInaFiT, a freeware tool to assess non-log-linear microbial survivor curves. Int. J. Food Microbiol. 102, 95-105. doi: 10.1016/j.ijfoodmicro.2004.11.038

Guranowski, A., Jakubowski, H., and Holler, E. (1983). Catabolism of diadenosine 5,5'"-P1,P4-tetraphosphate in procaryotes. J. Biol. Chem. 258, 14784-14789.

Guyer, M. S., Reed, R. R., Steitz, J. A., and Low, K. B. (1981). Identification of a sex-factor-affinity site in E. coli as $\gamma \delta$. Cold Spring Herb. Symp. Quant. Biol. 45, 135-140. doi: 10.1101/SQB.1981.045.01.022

Haberbeck, L. U., Oliveira, R. C., Vivijs, B., Wenseleers, T., Aertsen, A., Michiels, C., et al. (2015). Variability in growth/no growth boundaries of 188 different Escherichia coli strains reveals that approximately $75 \%$ have a higher growth probability under low pH conditions than E. coli O157:H7 strain ATCC 43888. Food Microbiol. 45, 222-230. doi: 10.1016/j.fm.2014.06.024

Hayes, E. T., Wilks, J. C., Sanfilippo, P., Yohannes, E., Tate, D. P., Jones, B. D., et al. (2006). Oxygen limitation modulates $\mathrm{pH}$ regulation of catabolism and hydrogenases, multidrug transporters, and envelope composition in Escherichia coli K-12. BMC Microbiol. 6:89. doi: 10.1186/1471-2180-6-89

Iyer, R., Williams, C., and Miller, C. (2003). Arginine-agmatine antiporter in extreme acid resistance in Escherichia coli. J. Bacteriol. 185, 6556-6561. doi: 10.1128/JB.185.22.6556-6561.2003

Johnstone, D. B., and Farr, S. B. (1991). AppppA binds to several proteins in Escherichia coli, including the heat shock and oxidative stress proteins DnaK, GroEL, E89, C45 and C40. EMBO J. 10, 3897-3904.

Joloba, M. L., Clemmer, K. M., Sledjeski, D. D., and Rather, P. N. (2004). Activation of the gab operon in an RpoS-dependent manner by mutations that truncate the inner core of lipopolysaccharide in Escherichia coli. J. Bacteriol. 186, 8542-8546. doi: 10.1128/JB.186.24.8542-8546.2004

Kadrmas, J. L., and Raetz, C. R. H. (1998). Enzymatic synthesis of lipopolysaccharide in Escherichia coli. Purification and properties of heptosyltransferase I. J. Biol. Chem. 273, 2799-2807. doi: 10.1074/jbc.273. 5.2799

Kanjee, U., and Houry, W. A. (2013). Mechanisms of acid resistance in Escherichia coli. Annu. Rev. Microbiol. 67, 65-81. doi: 10.1146/annurev-micro-092412155708

Klauck, E., Böhringer, J., and Hengge-Aronis, R. (1997). The LysR-like regulator LeuO in Escherichia coli is involved in the translational regulation of rpoS by affecting the expression of the small regulatory DsrA-RNA. Mol. Microbiol. 25, 559-569. doi: 10.1046/j.1365-2958.1997.4911852.x

Kleckner, N., Bender, J., and Gottesman, S. (1991). Uses of transposons with emphasis on Tn10. Methods Enzymol. 204, 139-180. doi: 10.1016/00766879(91)04009-D

Kwon, Y. M., and Ricke, S. C. (2000). Efficient amplification of multiple transposon-flanking sequences. J. Microbiol. Methods 41, 195-199. doi: 10.1016/S0167-7012(00)00159-7

Lease, R. A., Smith, D., McDonough, K., and Belfort, M. (2004). The small noncoding DsrA RNA is an acid resistance regulator in Escherichia coli. J. Bacteriol. 186, 6179-6185. doi: 10.1128/JB.186.18.6179-6185.2004

Lu, P., Ma, D., Chen, Y., Guo, Y., Chen, G. Q., Deng, H., et al. (2013). L-glutamine provides acid resistance for Escherichia coli through enzymatic release of ammonia. Cell Res. 23, 635-644. doi: 10.1038/cr.2013.13

Maurer, L. M., Yohannes, E., Bondurant, S. S., Radmacher, M., and Slonczewski, J. L. (2005). pH regulates genes for flagellar motility, catabolism, and 
oxidative stress in Escherichia coli K-12. J. Bacteriol. 187, 304-319. doi: 10.1128/JB.187.1.304-319.2005

McLennan, A. G., Barnes, L. D., Blackburn, G. M., Brenner, C., Guranowski, A., Miller, A. D., et al. (2001). Recent progress in the study of the intracellular functions of diadenosine polyphosphates. Drug Dev. Res. 52, 249-259. doi: $10.1002 /$ ddr. 1122

Moukadiri, I., Garzón, M. J., Björk, G. R., and Armengod, M. E. (2014). The output of the tRNA modification pathways controlled by the Escherichia coli MnmEG and $\mathrm{MnmC}$ enzymes depends on the growth conditions and the tRNA species. Nucleic Acids Res. 42, 2602-2623. doi: 10.1093/nar/gkt1228

Noguchi, K., Riggins, D. P., Eldahan, K. C., Kitko, R. D., and Slonczewski, J. L. (2010). Hydrogenase-3 contributes to anaerobic acid resistance of Escherichia coli. PLoS ONE 5:e10132. doi: 10.1371/journal.pone.0010132

Presser, K. A., Ross, T., and Ratkowsky, D. A. (1998). Modelling the growth limits (growth/no growth interface) of Escherichia coli as a function of temperature, $\mathrm{pH}$, lactic acid concentration, and water activity. Appl. Environ. Microbiol. 64, 1773-1779.

Richard, H., and Foster, J. W. (2004). Escherichia coli glutamate- and arginine-dependent acid resistance systems increase internal $\mathrm{pH}$ and reverse transmembrane potential. J. Bacteriol. 186, 6032-6041. doi: 10.1128/JB.186.18.6032-6041.2004

Rowbury, R. J. (2004). Enterobacterial responses to external protons, including responses that involve early warning against stress and the functioning of extracellular pheromones, alarmones and varisensors. Sci. Prog. 87, 193-225. doi: 10.3184/0036850047832 38535

Sambrook, J., Fritsch, E. F., and Maniatis, T. (1989). Molecular Cloning: A Laboratory Manual, 2nd Edn. Cold Spring Harbor, NY: Cold Spring Harbor Laboratory Press.

Shabala, L., and Ross, T. (2008). Cyclopropane fatty acids improve Escherichia coli survival in acidified minimal media by reducing membrane permeability to $\mathrm{H}+$ and enhanced ability to extrude H+. Res. Microbiol. 159, 458-461. doi: 10.1016/j.resmic.2008.04.011
Shi, X., and Bennett, G. N. (1995). Effects of multicopy LeuO on the expression of the acid-inducible lysine decarboxylase gene in Escherichia coli. J. Bacteriol. 177, 810-814.

Sun, Y., Fukamachi, T., Saito, H., and Kobayashi, H. (2012). Adenosine deamination increases the survival under acidic conditions in Escherichia coli. J. Appl. Microbiol. 112, 775-781. doi: 10.1111/j.1365-2672.2012.05246.x

Ude, S., Lassak, J., Starosta, A. L., Kraxenberger, T., Wilson, D. N., and Jung, K. (2013). Translation elongation factor EF-P alleviates ribosome stalling at polyproline stretches. Science 339, 82-85. doi: 10.1126/science.1228985

Ukuku, D. O., Zhang, H., and Huang, L. (2009). Growth parameters of Escherichia coli O157:H7, Salmonella spp., Listeria monocytogenes, and aerobic mesophilic bacteria of apple cider amended with nisin-EDTA. Foodborne Pathog. Dis. 6, 487-494. doi: 10.1089/fpd.2008.0233

Viala, J. P. M., Méresse, S., Pocachard, B., Guilhon, A. A., Aussel, L., and Barras, F. (2011). Sensing and adaptation to low $\mathrm{pH}$ mediated by inducible amino acid decarboxylases in Salmonella. PLOS ONE 6:e22397. doi: 10.1371/journal.pone.0022397

Wang, Y. (2002). The function of OmpA in Escherichia coli. Biochem. Biophys. Res. Commun. 292, 396-401. doi: 10.1006/bbrc.2002.6657

Zhao, B., and Houry, W. A. (2010). Acid stress response in enteropathogenic gammaproteobacteria: an aptitude for survival. Biochem. Cell Biol. 88, 301-314. doi: $10.1139 /$ o09-182

Conflict of Interest Statement: The authors declare that the research was conducted in the absence of any commercial or financial relationships that could be construed as a potential conflict of interest.

Copyright (c) 2016 Vivijs, Aertsen and Michiels. This is an open-access article distributed under the terms of the Creative Commons Attribution License (CC BY).

The use, distribution or reproduction in other forums is permitted, provided the original author(s) or licensor are credited and that the original publication in this journal is cited, in accordance with accepted academic practice. No use, distribution or reproduction is permitted which does not comply with these terms. 